\title{
Critical reflections on the PGCE (Foundation Phase) qualification in South Africa
}

Clare Verbeek, University of Cape Town.*

\begin{abstract}
There is a crisis in provision of quality teaching in the foundation phase of schooling in South Africa. This article argues that the Postgraduate Certificate in Education (Foundation Phase) (PGCE(FP)) has potential to help address this crisis. The article draws on data from university admission policies, focused discussion between teacher educators from six universities, and a survey of registered PGCE(FP) students at one of these institutions. Through an examination of criteria for admission to the qualification, the article considers which students could potentially be recruited into teaching via the PGCE(FP). The value of students' academic maturity is highlighted in relation to the duration and content of the curriculum, and in terms of knowledge and motivational effects on children taught by these teachers. It is recommended that admission criteria for the PGCE(FP) should allow recruitment of graduates from a wider variety of academic backgrounds, and it is argued that this qualification should be seen as part of a continuum of professional learning and that teachers with a baccalaureate are well skilled to be active lifelong professional learners. Specific suggestions are made for further research to develop a full analysis of the distinct contribution the PGCE(FP) can make to the early years teaching profession.
\end{abstract}

Keywords: PGCE, foundation phase, Initial Teacher Education, admission criteria, early years

*Email: clare.verbeek@uct.ac.za

South African Journal of Childhood Education | 2014 4(3): 37-51 | ISSN: 2223-7674 |৫ UJ

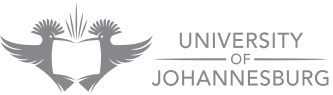




\section{Introduction}

When the South African Department of Higher Education and Training (DHET), in partnership with the European Union (EU), set up the ambitious support programme 'Strengthening Foundation Phase Teacher Education' in 2011 (Green, Parker, Deacon \& Hall 2011; RSA DHET 2012), it signalled a crucial and growing recognition in South Africa that the foundations for success in schooling are laid in the early years of a child's life. During the first nine or so years of life, children experience massive cognitive, biological and social development. Their early experiences at home, in the community and in the education system impact significantly on their healthy, happy and productive participation in society, both as children and as adults. During these early years, children begin to develop the independence of thought and the attitude and ability to make judgements that are necessary for participation in a democracy (Linnington, Excell \& Murris 2011). Crucial in this regard is the independent and confident use of the basic tools of language, reading, writing and mathematics, which are initially developed at home and during the foundation years of schooling. During these early years children also consolidate the self-esteem, confidence and selfcontrol necessary to use these basic tools to think and to communicate their thinking with others (Barnett, Jung, Yarosz, Thomas, Hornbeck \& Stechuk 2008; Bodrova \& Leong 2007). In addition, it is during the formative early years of schooling that children, particularly those from families and communities without strong histories of formal education, develop a sense of what schooling is about and come to establish routines, habits and processes for learning in the context of classrooms full of other children, thus laying the basis for academic progress. For all these reasons, children in the foundation phase in particular require and deserve quality teaching that promotes effective and rewarding learning.

However, while there are pockets of excellent foundation phase teaching in South Africa, provision of quality education is profoundly unequal (Van der Berg 2014). In general there are crises in the supply of teachers with appropriate language backgrounds for teaching grades $\mathrm{R}$ to 3 through the home language, as well as in the provision of quality teaching (Bloch 2009; Fleisch 2008; Green et al 2011; Taylor 2013). This is indicated by comparatively poor results of South African children in international, national and even provincial language and mathematics tests at grade 3, 6 and 9 levels (Hoadley 2013; Spaull 2011, 2013; Taylor 2006).

Work in the field of sociology of education has revealed complex mechanisms by which inequality is perpetuated in and through schooling (Hoadley \& Ensor 2009; Rose 2010). Quality early schooling experiences are particularly significant in relation to progress towards national goals of social justice, equality and participatory democracy. However, stratification of educational inputs and outcomes in South Africa continues to thwart this project at the levels of the system, curriculum and classroom. Research about accumulated advantage in literacy development suggests that children who fall behind expectations in the early years of schooling seldom catch up, and indeed that their failure is compounded over time (Mourshed, Chijioke \& Barber 2010). This is described as the 'Matthew effect', whereby the rich get richer and the poor get 
poorer (Cunningham \& Stanovich 1997; Rigney 2010; Stanovich 2004). While success in schooling results from a complex interplay of factors, teachers and teaching are central to quality schooling provision. There is substantial evidence that teachers and teaching matter to student learning (Bransford, Darling-Hammond \& LePage 2005; Timperley \& Alton-Lee 2008). The supply of teachers who are adequately prepared to deliver contextually appropriate, high quality education in the early years of schooling is thus a priority both in terms of the impact on individual children and in terms of social justice in society as a whole. Recognising this, the Strengthening Foundation Phase Teacher Education programme has directed significant energy towards expanding initial teacher education provision for the foundation phase, including the expanded provision of the one-year Postgraduate Certificate in Education (Foundation Phase) or PGCE (FP) programme.

At the foundation phase level, the PGCE is a relatively uncommon teacher qualification route. I would argue that its potential is also relatively poorly understood in the profession. The purpose of this article is to open the way to a more nuanced appreciation of the contribution that this qualification might make to education in the South African context. In the article I will do this by reflecting critically on a key dilemma that teacher educators involved in the PGCE(FP) have been grappling with, namely the question of who should be admitted to the PGCE(FP) (Joubert 2013; Verbeek 2013). The article uses this dilemma as a springboard to explore how the PGCE(FP) can contribute towards addressing the twin crises of quality teaching in foundation phase classrooms and the supply of teachers for the foundation phase across significantly diverse and unequal school contexts in South Africa.

The article draws on qualitative data obtained from a variety of sources in 2013 and 2014. Focused discussion by twelve PGCE(FP) teacher educators from six universities in March 2013, recorded by Verbeek (2013) and reported on by Joubert (2013), as well as official websites of these programmes, provided data about admission criteria. A formally administered written survey of all the PGCE(FP) students registered for full-time contact study at one of these institutions in 2014 provided, by means of open-ended questions, data about these students' perceptions of the relevance of their undergraduate courses to their initial teacher education and of the usefulness of the admission criteria to their professional education. It is a limitation that this data set originated in one institution only, and no claims are made about generalisability. The article also draws on personal communication with a number of school principals, foundation phase heads of department, and provincial education department officials regarding the placement of PGCE(FP) graduates. The identities of these individuals are not revealed in this paper. Content analysis of these data sets was achieved by the identification of themes.

\section{The PGCE (FP): a controversial qualification}

In South Africa there are at present three possible routes of study by which a candidate teacher can achieve qualified teacher status (QTS): the four-year Bachelor 
of Education degree (BEd ); a three-year degree capped by the one-year Postgraduate Certificate in Education (PGCE); and, for a limited period of time, in order to deal with issues of redress and to accommodate those who, for largely historical reasons, have been teaching without qualified teacher status, the National Professional Diploma in Education (NPDE) followed by an Advanced Certificate in Teaching (ACT). The BEd and the PGCE qualifications are both pegged at level 7 on the National Qualifications Framework (NQF) and are broadly aligned with international practice. They are the result of decades of work to create from the fragmented legacy of apartheid education provision a unified system that can serve the needs of children in multiple, still starkly unequal contexts in South Africa. I would argue that the coexistence of these different pathways to QTS are beneficial to the education system as a whole, ensuring access to diverse groups of teachers with different academic histories as well as epistemological and methodological variety in the teaching profession. While striving for quality and minimum standards, it is a strength that the education system in South Africa has not rigidly standardised and homogenised teacher training, as one size cannot fit all.

The PGCE brings into the profession individuals from particular, and often wideranging, backgrounds, who might otherwise not have become teachers. Examples are the numerous graduates who start teaching without a professional qualification, sometimes purely out of commitment to education and children and sometimes because jobs are hard to find even for baccalaureus graduates. It also provides an opportunity for people to change professions mid-career, which again brings valuable diversity and experience into the schooling system. In addition, as I will discuss in this article, the foundation phase qualification also brings graduates who have not studied traditional school subjects into the system. Such graduates would probably not enter teaching if they had to retrain with a four-year degree.

Traditionally, the PGCE has been used to train subject specialists for the senior school (CHE 2010), on the assumption that they would have gained strong disciplinary and subject knowledge via their first degree and that they can convert this knowledge to teaching 'capital'. Thus, the PGCE would be a programme in which they could focus largely on understanding education and educational contexts and on learning how to teach the subject content. It is for this reason that the PGCE is more controversial as a vehicle for training foundation phase teachers. Practicing teachers whom I have encountered in my research and higher education practice often take strong positions against the qualification. Some principals, HODs and teachers whom I (and my colleagues) have met with in research and practice question the efficacy of a PGCE qualification for the foundation phase. Resistance to the PGCE (FP) is expressed along the following lines: "It is simply not possible to learn everything a foundation phase teacher needs to know in one year" (personal communication, teacher A 2015); "PGCEs only have two practice teaching periods. This is not enough time in the classroom to know what to do" (personal communication, HOD A 2015); "PGCE graduates learn too much theory and do not get enough practice. They do not know what to do in the classroom" (personal communication, Principal 2015); "In my 4 year training we made all the necessary teaching aids. PGCEs don't have time to do 
this and are therefore not fully prepared" (personal communication, HOD B 2015); or "If they were really committed to teaching young kids they would have done an education degree from the start" (personal communication, teacher B 2015). These comments resonate with four interdependent questions that teacher educators are grappling with, namely: 1) what initial preparation do students need to have in order to be successful foundation phase teachers; 2) what is the relationship between theory and practice in this preparation; 3) can this preparation be achieved in one year; and 4) who should be admitted to this training (Verbeek 2013)? There is a dialectical relationship in purposeful teaching between what is taught, how it is taught, and who is taught. Successful teaching takes into account who the learners are, as well as what they are to be taught. The discussion that follows therefore begins by considering who could potentially be admitted into the PGCE(FP) before briefly exploring, in the light of this, what and how they might be taught.

Out of the 33,400 students in South Africa who graduated as qualified teachers in 2010 , only 1,275 specialised in teaching in the foundation phase (grades R-3) (Green et al 2011). At that point, these new teachers represented only $27.8 \%$ of the estimated need for qualified foundation phase teachers (ibid). Eighty-two per cent ( $82 \%$ ) of these foundation phase graduates completed a four-year BEd degree at one of thirteen tertiary education institutions (ibid), while the other $18 \%$ or 227 students countrywide completed a one-year Postgraduate Certificate in Education (PGCE), after having completed at least a bachelor's degree. In other words, 3.5\% of all newly qualified teachers in 2010 were PGCE(FP) graduates. More recent work on teacher supply and demand calculated a supply-demand gap of almost 2,500 too few foundation phase teachers in 2012, and disaggregated this figure to show that $92 \%$ of the need was for speakers of African languages (Green 2014).

Six South African universities currently offer the PGCE(FP) through various modes of delivery, including one distance, one mixed-mode, one part-time contact, and two bilingual programmes. Fifty per cent (50\%) of PGCE (FP) students in 2010 were registered at a distance education institution. The South African Council of Higher Education's (CHE) review of academic and professional programmes in education (2010), reporting before any of the universities offered dedicated PGCE(FP) programmes, noted great variability in the design of PGCE provision. As reported by teacher educators in a 2013 workshop (Joubert 2013; Verbeek 2013), this remains a feature of the FP programmes. It is therefore important not to make assumptions that the graduates of one programme can be compared with those of another. It is outside the scope of this article to comment on design of PGCE programmes, but it is useful in terms of the arguments that follow regarding admission criteria to note that international literature indicates that PGCE programmes should have five key features: conceptual coherence; a strong link between taught modules and work-based learning; be designed to encourage and develop critical reflection and self-reflexivity; should constitute students as learners positioned to engage fruitfully in continuing professional development and adapt to changes in curricula and new trends in 
education; and should give students as novice practitioners a broad understanding of education as a practice and competence (CHE 2010).

\section{The PGCE (FP) student as baccalaureus graduate}

The minimum entrance requirement to a PGCE is a bachelor's degree. Students may therefore generally be described as academically experienced with deep content and disciplinary knowledge in at least one field of study. This is valuable, as teachers need a deep understanding of fundamental concepts in a discipline, how they are organised and how they relate to each other in order to use their subject matter knowledge for teaching (Bertram 2011; Shulman 1987). In addition, as baccalaureus graduates, PGCE students have ideally already learned to think critically, to find and access information and to study independently (Griesel \& Parker 2009). However, there are various types of higher education institutions in South Africa, including traditional, comprehensive universities as well as universities of technology. Further research is needed regarding the nature and content of degrees obtained from different types of institutions, including the graduate attributes of each, in order to inform design of PGCE programmes.

Bringing students with such academic backgrounds into teaching also helps to strengthen the profession. This is of particular importance at the foundation phase level, where teachers have historically been the least well qualified and seen as the least prestigious (Petersen \& Petker 2011). Students' academic strength and maturity is of value to the education system in at least three respects: at the level of institutions of higher learning, it influences the design and content of teacher development curricula, while at the level of schools it has both knowledge and motivational effects on children taught by these teachers; in addition, such students have the potential to contribute much needed research in the field of early years education.

Data collected as part of this study through a small-scale survey of all students who had just completed one of the country's PGCE(FP) programmes, corroborates these arguments. Most students believed that the greatest value of their first degrees to their initial teacher preparation lay in the development of academic and critical thinking skills. They highlighted the following important attributes, developed in the course of undergraduate studies, and which they felt they brought with them into the PGCE(FP): familiarity with academic processes and expectations (including time management and discipline); skills in reading and research; careful critical thinking; the ability to develop and validate a position; critical engagement with topics; examining information with intention and purpose in mind; and academic writing skills. Students felt that these skills enhanced their learning in the PGCE and increased their confidence about being able to solve problems they might encounter in teaching. These are valuable lifelong learning skills that enable teachers to find and evaluate information, and could therefore be seen as a crucial aspect of the development of critical and creative teachers who are prepared for lifelong learning. They also make it possible for teacher training curricula to draw on these skills. This is significant in relation to the 
question of the duration of the PGCE: it is one of the factors which make it possible for the training to be relatively short.

If candidates have gained both broad and deep disciplinary knowledge at undergraduate level, they arguably have the potential to inspire children's sense of wonder and interest in these fields. For example, teachers who have an interest and knowledge in the sciences can motivate and stimulate children's learning in this often neglected field in early years education. Of particular importance to foundation phase teaching, teachers who have a strong academic background are likely to have an established culture of reading and broad general knowledge. It is crucial that teachers should model a culture of reading if they aim to foster the development of such a culture among their students (Rimensberger 2014). General or background knowledge is essential for the comprehension of a wide range of texts (Mannes \& St George 2014). In addition, students who have already completed a first degree are likely to have been well prepared as both independent and collaborative learners on a path of lifelong learning. They are therefore expected to be able to further develop their knowledge about teaching and learning through formal and informal study and self-reflection. Thus the general benefits to the education system of the postgraduate nature of the PGCE are clear.

With regard to the issue of entrance qualifications, the forgoing discussion suggests that students should be admitted to the PGCE(FP) on the basis of having completed a coherent academic bachelor's degree.

\section{Content knowledge for FP teaching}

A number of researchers and commentators have attributed failures in the South African education system to poor teacher content knowledge (Taylor 2013; Shalem \& Hoadley 2009; Taylor 2013; Taylor \& Taylor 2013). Based on the foregoing argument that the PGCE is designed on the basis that content knowledge is developed in the undergraduate degree, the question of what constitutes this content knowledge for teaching in the foundation phase is important. Conventional wisdom would hold that anyone who can read, write and do basic mathematics has the subject content knowledge necessary to teach foundation phase children. Morrow (2007:52) points out that the curriculum for basic education has remained "remarkably stable" across the world and over the past century at least, consisting of "generic decoding skills" (ibid:64) in literacy and mathematics. Any entrant to the PGCE programme would certainly have this content knowledge. However, this knowledge is often so much second nature to graduate students that they find it difficult to identify the building blocks that constitute their advanced skill. For example, PGCE students in my class can all read at an advanced level, but half were not able to pass at first attempt a test on phonics knowledge, although they arguably made at least some use of this on a daily basis in the process of reading. In other words, when considering content knowledge, declarative and procedural knowledge need to be disaggregated and teaching time needs to be devoted to developing metalinguistic awareness about these basic 
skills. However, as evidenced by the systemic tests which show that South African children are failing to achieve expected standards of education, more is required than application of these skills. Teachers' content knowledge for foundation phase teaching requires a broader conception of literacy, which emphasises meaning-making and necessitates the development of independent thinking, thus going beyond only teaching the initial mechanics of reading. Similarly, a deep sense of numerosity and an understanding of what mathematics is about (its grammar and vocabulary), over and above the application of mathematical operations, is critical teacher knowledge to enable quality teaching in the foundation phase. In addition, teachers need knowledge about questioning and their own higher order questioning skills need to be developed so as to grow children's capacity for independent critical and imaginative thinking from the early years (Murris 2014). Furthermore, as Murris and Verbeek (2014) propose, foundation phase teachers need deep knowledge of children and conceptions of childhood, including how children learn and develop.

The question then arises: is such content knowledge likely to have been developed in any undergraduate degree outside the field of education? There is seldom a direct correspondence between the content of first degrees and the content for teaching in the foundation phase. For example, the English (or any other language) that students may have studied in their bachelor's degree is unlikely to have covered children's literature or to have focused on the alphabetic principle or phonemic awareness, which would from part of the content of learning to teach reading in the foundation phase. Likewise, university-level mathematics is clearly far in advance of foundation phase maths. Similar arguments could be made in respect of other subjects. However, as argued earlier in this paper, advanced study in any field provides the future teacher with an understanding of knowledge structures, issues and procedures to conceptualise their work in the foundation phase classroom. This provides strength to their training and to the profession, as the teacher has a vision of where the young child's knowledge might lead in future as well as a sense of how what is learned in the early years of schooling builds towards this.

Content knowledge and pedagogical content knowledge (PCK) are particularly closely intertwined in foundation phase teaching. For example, should knowledge of how children learn to read be regarded as content or pedagogical content knowledge? As Bertram (2011) points out, PCK is a contested term. As signalled by the opinions of practicing teachers reported in this article, the teaching profession expects that foundation phase teachers should have broad pedagogical content knowledge as well as general pedagogical knowledge in order to teach effectively. Therefore, while the design of the PGCE(FP) can assume prior basic content knowledge, particular emphasis needs to be devoted to developing pedagogical content knowledge. This has implications for the duration of the qualification, which is discussed later in this article.

In the light of the arguments about the value of the postgraduate nature of the PGCE (FP) forwarded thus far, the brief consideration of what it is that students need to know and teach, and the assertion that there is seldom direct correspondence 
between this knowledge and undergraduate courses, the article now considers implications for admission criteria to the PGCE(FP).

\section{Flexible admission criteria}

The question of admission criteria to the PGCE(FP) is a burning issue for teacher educators at all the universities that offer the programme (Joubert 2013). National policy prescribes that the minimum admission requirement for the professionallyfocused PGCE is an "appropriate diploma or degree", which ensures "sufficient disciplinary learning" to effectively teach Literacy, Mathematics and Life Skills in the foundation phase (RSA DHET 2011:24), and leaves it up to the institution of higher learning to determine the extent to which the embedded content in the degree is sufficient for teaching at the foundation phase level. In 2013 this was variously interpreted: at one university, the admission requirement was a degree with two official languages at first-year level plus one other school subject; at another, it was a degree plus two school subjects, one of which should be at second-year level; at a third, preference was given to students with psychology and undergraduate education subjects; a fourth preferred psychology and linguistics; and one preferred graduates who had studied psychology.

Unlike PGCEs specialising in other phases of schooling, students may be admitted to the PGCE(FP) on the basis of having studied undergraduate psychology. In the small-scale survey of PGCE(FP) conducted as part of this study, half of the respondents would not have been admitted to the programme were it not for this provision. This corroborates the point argued earlier in this paper that the PGCE(FP) has the potential to recruit teachers into the system who might otherwise not have joined the profession. In the case of psychology graduates, however, this is potentially a double-edged sword, as it has been argued that many such graduates undertake PGCE study because it is a requirement for admission to Educational Psychology honours programmes. While such professionals provide a valuable auxiliary service to the education system, they are lost to the teaching profession per se (Verbeek 2013).

The preference for psychology graduates reveals a policy assumption that the field of psychology provides relevant content knowledge needed to teach foundation phase children. Students surveyed reported that having completed various courses in developmental, organisational, social or child psychology provided valuable background to their PGCE(FP) studies. In particular, they reported that their psychology studies deepened their understanding of the development of children, including emotional, social, behavioural and cognitive development; how children learn, learning difficulties and barriers to learning; the importance of social and environmental backgrounds; the importance of understanding the child as a whole; and inter- and intrapersonal dynamics in the school, the classroom and the community. Student opinion in the small-scale survey also suggested that a useful entrance criterion for the PGCE(FP) could be interest in and commitment to working with young children. 
From the above it can be concluded that although the entrance criteria for the PGCE (FP) signal a valuing of the discipline of psychology for teaching in the foundation phase, no common disciplinary basis exists from which the PGCE(FP) curriculum can be designed, except for taking into account the general academic strengths that graduates may be assumed to have, which include the ability to read, write and think, including to think mathematically, at least at a basic level. In the light of this, and considering the value of the qualification in bringing an untapped source of teachers into the education system, academics at the focused discussion proposed that universities should be more flexible in their interpretation of what constitutes an appropriate prior degree for PGCE(FP) candidates, reporting that some of their best students had previously trained as lawyers, engineers or scientists (Verbeek 2013).

\section{Can foundation phase teachers be (pedagogically) prepared in one year?}

Three lines of argument are presented to suggest that it is indeed possible to train foundation phase teachers in the relatively short period of one year, assuming that they have the graduate attributes identified previously. The first argument relates to who PGCE students are and the fact that initial teacher education is part of a continuum of professional development; the second relates to a distinction between education and training; and the third relates to the nature of the PGCE practicum.

Teachers bring agency (Ebrahim, Verbeek \& Mashiya 2011); judgement (Murris \& Verbeek 2014); creativity, skill, emotion, intention, intellectual challenge, function, expression and degrees of freedom (Lupton 2012), as well as past experience to every class they teach. Initial teacher education prepares teachers by consolidating students' understanding of what is to be taught; familiarising them with some of the tools and delivery techniques they may use as a point of departure in this creative process; making them aware of what has been shown to work or not work; helping them to better understand their pupils and the context in which they teach; clarifying the expectations of the profession; developing their ability to reflect critically on and learn from their teaching; and providing them with an introductory experience of schools and supported early teaching opportunities. But no initial teacher education programme, no matter how long or comprehensive, can produce a teacher who 'knows' or is able to 'do' everything, precisely because teaching is practiced in context. Consequently, learning to teach is a lifelong process and initial teacher education should be seen as part of a continuum of development, both formal and non-formal, including induction and continuing professional development until the end of the teacher's career.

Viewing teacher development as an ongoing process is particularly important when we consider the fact that curricula and policies change, that 'teaching methods' move in and out of favour, and that new commercially available education materials (or brands) are continually coming onto the market. Programmes for continuing teacher education address these changes. Prolific information, lesson plans and 
activities for teaching foundation phase content are available on the Internet and in published teachers' guides. Teachers must be able to interact with these materials as agents and make wise educational judgements about them on the basis of sound knowledge. Importantly, teachers who have the kind of degree that is assumed in this study and who qualify via a PGCE, are able to research, discern and engage in self-study, particularly when supported by professional learning communities in the schools themselves. While it cannot be assumed that conditions in schools are conducive to this, it is indeed the intention of policy that such conditions be promoted and developed. Design of PGCE curricula should include practice in working in such professional learning communities.

An initial teacher development curriculum which focuses on underlying understandings and principles, rather than on numerous 'methods', is a second factor that makes it possible for the PGCE to be achieved in one year. This is education, as opposed to training, and provides a basis from which wise educational judgements can be made. Murris and Verbeek (2014) set out five possible principles for a foundation phase curriculum: participatory democracy and social justice, intellectual integrity, reflexivity, narrativity, and aesthetic and embodied learning. Central to these principles are relationships, for example, between teacher and student, student and text, student and environment, mind and body, and theory and practice. It is by developing such principles and relationships that the PGCE(FP) student comes to embody the basic competences of a beginning teacher set out by policy in South Africa - which include having sound subject knowledge and knowing how to select, sequence and pace their teaching in relation to both the subject and learners' needs (RSA DHET 2011:53) - and is able to be an active agent in the classroom. With a focus on such principles, initial teacher education can be achieved in one year.

In addition, the possibility of quality PGCE training for foundation phase teachers depends on the nature of the practicum experience, which the CHE (2010) identified as a critical factor in beginning teacher confidence and performance. As the CHE review noted, there is great variation across universities in this regard. Current policy aims to align this by at least specifying minimum periods of work-integrated learning (RSA DHET 2011). However, particularly for large-scale and distance programmes, geographical, financial and administrative constraints on university supervision, combined with constraints relating to the functionality of schools (Christie, Butler \& Potterton 2007), the quality of existing teaching and the role of collaborating teachers, are likely to continue to threaten quality practicum experience and therefore the quality of PGCE(FP) offerings. This needs to be a serious focus of attention in PGCE programme design as well as programme monitoring and evaluation.

\section{Conclusion and recommendations}

This article has argued that the potential contribution of the PGCE(FP) has not been sufficiently recognised by the teaching profession. Prejudice from within the profession about the length of the PGCE(FP) programme appears to result from 
preconceived ideas about how people learn to teach; what teacher training (as opposed to education) should involve; and whether relevant content knowledge is adequately provided by undergraduate degrees from all South African universities. We need to open up discussion about what a newly qualified foundation phase teacher should be able to know and do, and the constrained time period available for the postgraduate certificate provides an important challenge and valuable opportunity for teacher educators to identify what is essential. This may provide important insights for other initial teacher development qualifications as well.

Although a relatively small proportion of foundation phase teachers complete the PGCE(FP) qualification, it can fill crucial gaps in teacher supply by bringing an otherwise untapped stream of committed and capable teachers into foundation phase education. The PGCE in general should bring teachers who are strong academically into the system, which has the potential to strengthen the profession. This is particularly important in foundation phase education, where teachers have historically been less well qualified and treated as less prestigious, and the research tradition has been historically weak. Benefits are also proffered to the system by the variety and depth of the initial degrees of PGCE(FP)-trained teachers, as they typically bring to their classrooms broad general and deep disciplinary knowledge, as well as interest and sometimes experience in fields other than education. The PGCE brings into the system teachers who have been exposed during their first degree studies to people, ideas and approaches other than what they might encounter in a school of education. Moreover, students who have already completed a first degree are likely to have been well prepared as both independent and collaborative learners on a path of lifelong learning. They can therefore be expected to continue to develop their knowledge about teaching and learning through formal and informal study and self-reflection throughout their careers, particularly if professional learning communities have been established in schools.

The PGCE(FP) also has the potential to contribute to resolving the crisis of quality of foundation phase education in South Africa. There is no empirical evidence that teachers prepared in this fashion are any less able to deliver sustained quality education over time, although this needs further investigation.

Drawing on these conclusions, some specific recommendations for action and further research can be made. Firstly, admission criteria for the PGCE(FP) should allow recruitment of graduates from a wide variety of academic backgrounds. Secondly, rather than comparing graduates with different types of initial teacher qualifications, the significant specific contributions and challenges of each qualification model should be recognised by the profession. To promote this, further research is needed about both the contributions and the challenges of the PGCE(FP) qualification in particular. One critical challenge for consideration is how PGCE(FP) programmes may recruit and prepare teachers to make a contribution across the profoundly unequal community and schooling contexts in South Africa. The DHET/EU project has focused on the need to strengthen the training of teachers who are committed and able to teach through the medium of an African language in the foundation phase in rural or township 
schools. This remains an ongoing challenge, particularly for PGCE(FP) programmes. However, other challenges of teacher preparation for these contexts deserve increased attention, for example, models of support for student teaching practice in such challenging contexts.

\section{References}

Barnett, W.S., Jung, K., Yarosz, D., Thomas, J., Hornbeck, A. \& Stechuk, R. 2008. Educational effects of the Tools of the Mind curriculum: A randomized trial. Early Childhood Research Quarterly, 23:299-313.

Bertram, C. 2011. What does research say about teacher learning and teacher knowledge? Implications for professional development in South Africa. Journal of Education, (1)52:3-26.

Bloch, G. 2009. The toxic mix: What's wrong with South Africa's schools and how to fix it. Cape Town: Tafelberg.

Bodrova, E. \& Leong, D.J. 2007. Tools of the mind. Columbus, OH: Prentice Hall.

Bransford, J., Darling-Hammond, L. \& Lepage, P. 2005. Introduction. In L. DarlingHammond \& J. Bransford (Eds.), Preparing teachers for a changing world: What teachers should learn and be able to do. San Franscisco, CA: Jossey-Bass. 1-39.

CHE (South African Council on Higher Education). 2010. Report on the National Review of Academic and Professional Programmes in Education. Pretoria: CHE.

Christie, P., Butler, D. \& Potterton, M. 2007. Schools that work. Report of the Ministerial Committee. Pretoria: Government Printers.

Cunningham, A. \& Stanovich, K.E. 1997. Early reading acquisition and its relation to reading experience and ability 10 years later. Developmental Psychology, 33:934-945.

Ebrahim, H., Verbeek, C. \& Mashiya, J.N. 2011. Enabling roles to reclaim teacher agency: Insights from the Advanced Certificate in Teaching (Foundation Phase). Perspectives in Education, 29(4):58-65.

Fleisch, B. 2008. Primary education in crisis: Why South African schoolchildren underachieve in reading and mathematics. Pretoria: Juta.

Green, W. 2014. Teacher supply and demand. Funza Lushaka Bursary Scheme National Workshop. Pretoria.

Green, W., Parker, D., Deacon, R. \& Hall, G. 2011. Foundation phase teacher provision by public higher education institutions in South Africa. South African Journal of Childhood Education, 1(1):109-121.

Griesel, H. \& Parker, B. 2009. Graduate attributes: A baseline study on South African graduates from the perspective of employers. Pretoria: Higher Education South Africa \& The South African Qualifications Authority (SAQA).

Hoadley, U. \& Ensor, P. 2009. Teachers' social class, professional dispositions and pedagogic practice. Teaching and Teacher Education, 25: 876-886. 
Hoadley, U. 2013. Building strong foundations: Improving the quality of early education. In L. Berry, L. Biersteker, H. Dawes, L. Lake \& C. Smith (Eds.), South African Child Gauge. Cape Town: Children's Institute. 72-77.

Joubert, I. 2013. Inter-institutional workshop held on PGCE. In-tuition Newsletter. Pretoria: University of Pretoria.

Linnington, V., Excell, L. \& Murris, K. 2011. Education for Participatory Democracy: a Grade R Perspective. Special Issue: Perspectives in Education, 29(1):36-45.

Lupton, M. 2012. Reclaiming the art of teaching. Teaching in Higher Education, 18:156-166.

Mannes, S. \& St George, M. 2014. Effects of prior knowledge on text comprehension: A simple modelling approach. In B. Britton \& A. Graesser (Eds.), Models of understanding text. New York: Psychology Press. 115-140.

Morrow, W. 2007. Learning to teach in South Africa. Cape Town: HSRC Press.

Mourshed, M., Chijioke, C. \& Barber, M. 2010. How the world's most improved education systems keep getting better. London: McKinsey Education.

Murris, K. \& Verbeek, C. 2014. A foundation for foundation phase teacher education: Making wise educational judgements. South African Journal of Childhood Education, 4(2):1-17.

Murris, K. 2014. Philosophy with children: Part of the solution to the early literacy education crisis in South Africa. European Early Education Research Journal. Retrieved from http://www.tandfonline.com/doi/abs/10.1080/1350293X.2014. 970856\#.VLgrOEeUd1a (accessed 10 December 2014).

Petersen, N. \& Petker, J. 2011. Foundation phase teaching as a career choice: Building the nation where it is needed. Education as Change, 15(sup1):S49-S61.

Rigney, D. 2010. The Matthew effect: How advantage begets further advantage. Columbia: Columbia University Press.

Rimensberger, N. 2014. Reading is very important, but...: Taking stock of South African student teachers' reading habits. Reading \& Writing 5(1). Retrieved from http://www.rw.org.za/index.php/rw/article/view/50/116 (accessed 1 December 2014).

Rose, D. 2010. Beating educational inequality with an integrated reading pedagogy. In F. Christie \& A. Simpson (Eds.), Literacy and social responsibility: Multiple perspectives. London: Equinox. 101-115.

RSA DHET (Republic of South Africa. Department of Higher Education and Training). 2011. Minimum Requirements for Teacher Education Qualifications. Government Gazette Vol. 553, No. 34467. Pretoria: Government Printers.

RSA DHET (Republic of South Africa. Department of Higher Education and Training). 2012. European Union Primary Sector Support Programme: Strengthening Foundation Phase Teacher Education. First year progress report. Pretoria: DHET.

Shalem, Y. \& Hoadley, U. 2009. The dual economy of schooling and teacher morale in South Africa. International Studies in Sociology of Education, 19(2):115-130.

Shulman, L.S. 1987. Knowledge and teaching: Foundations of the new reform. Harvard 
Educational Review, 57(1):1-22.

Spaull, N. 2011. A preliminary analysis of SACMEQ III South Africa. Stellenbosch: University of Stellenbosch Department of Economics.

Spaull, N. 2013. South Africa's Education Crisis: The quality of education in South Africa, 1994-2011. Johannesburg: Centre for Development Enterprise.

Stanovich, K.E. 2004. Matthew effects in reading: Some consequences of individual differences in the acquisition of literacy. In R.B. Ruddell \& N.J. Unrau (Eds.), Theoretical models and processes of reading. Fifth edition. Newark: International Reading Association. 454-516.

Taylor, N. \& Taylor, S. 2013. Teacher knowledge and professional habitus. In N. Taylor, S. van der Berg \& T. Mabogoane (Eds.), Creating Effective Schools. Cape Town: Pearson. $\mathrm{Xx}-\mathrm{x} \mathrm{x}$.

Taylor, N. 2006. Equity, efficiency and the development of South African schools. In T. Townsend (Ed.), International handbook of school effectiveness and improvement. Dordrecht: Springer. 523-540.

Taylor, N. 2013. NEEDU National Report 2012: The state of literacy teaching and learning in the foundation phase. Pretoria: National Education Evaluation and Development Unit (NEEDU).

Timperley, H. \& Alton-Lee, A. 2008. Reframing teacher professional learning: An alternative policy approach to strengthening valued outcomes for diverse learners. Review of Research in Education, 32:328-369.

Van Der Berg, S. 2014. The impact of the introduction of grade R on learning outcomes. Stellenbosch: Stellenbosch University, Research on Socio-Economic Policy (ReSEP).

Verbeek, C. 2013. Unpublished report on meeting of PGCE(FP) teacher educators from six universities, March 2013. Cape Town: University of Cape Town. 